\title{
Arts and Community Work for Promoting Resilience
}

\author{
Venkat Pulla ${ }^{1, *}$, Anne Riggs ${ }^{2}$ \\ ${ }^{1}$ Coordinator, Social Work Discipline, Australian Catholic University, Brisbane \\ ${ }^{2}$ Artists in Community International, Australia \\ *Corresponding Author: Venkat.pulla@acu.edu.au
}

\begin{abstract}
This paper discusses the role of visual and performing arts in regenerating and developing communities and the opportunity for creative collaborations between arts and strengths based social work practices in community development. The visual and performing arts have resided in abundance on the fringe of communities and community development and remain as a tool to release the untapped cultural capital. The paper identifies commonalities and shared concerns between arts and strengths based social work to present a practice narrative. We include voices from the marginalized individuals and communities to strengthen our argument for consideration of arts practice within the prevailing ethos of social work and community development
\end{abstract}

Keywords Resilience, Arts Practice, Community Development, Strengths Approach

\section{Introduction}

An early 20 century psychiatrist and art historian, Dr Hans Prinzhorn, whose work pre-dates the concept of art therapy, provides an interesting intersection between art and its therapeutic utility to the community (Maizels, 1996). He accumulated a vast collection of artworks made by patients within institutions, generally not made as part of treatment but as a way to explore the creative drive. In identifying a number of specific urges that drive creativity, the expressive, playful/active, decorative or ornamental, ordering, copying and the need for symbols, he concludes that creativity "is an essential human trait, found not only in the realm of the cultured or educated, but ... present within each of us from childhood" (Maizels, 1996, p. 15). We can see here the beginnings of a rationale for a role for arts practice in building community in conjunction with social work practice, with individuals and communities in which we know creativity is an inherent component of their human psyche. We also recognise the biological need to express. Arts practice and social work in communities, particularly social work that is underpinned by strengths based practice, are indeed both focused on creativity and expression.
Communities survive, thrive and flourish through this process and we recognise creativity as the innate capacity to think and act in original ways, to be inventive, to be imaginative and to find new and original solutions to needs, problems and forms of expression. It can be used in all activities. Its processes and outcomes are meaningful to its user and generate positive feelings (Schmid, 2005). When creativity is adequately expressed through every day activities, it has a major impact on health and wellbeing. Manifestations of creativity can depend on the culture and society in which we live and on the social and economic values that can predicate the level of creative response in our societies as well as our social response. Strengths based practice in social work is that which is pervaded by the belief that people have the personal strengths and resources to promote their own recovery and build resilience with practitioners employing therapeutic modalities that foster and empower these inherent strengths (Pulla, 2012).

The impetus to write this article together arose out of series of previous collaborations through conference presentations and reviewing the role of art in building coping, resilience and advancing hope in many of our social work clients (Riggs, 2010, Riggs, 2013, Pulla, 2010, Pulla, 2013). For this article we discuss art as a means to community development as has been utilised in many communities by the second author and with performing artist, Alex Pinder, in communities of Nepali people, with children in India and with women survivors of sexual assault It is the use of participants' non-textual reflections and the colourful artistic representations of their minds and thinking that allows us to better understand their coping and resilience throughout their journeys to date and into the future and how arts practice has contributed to that.

lmplementing change in pockets of disadvantage is complex. Children and families from impoverished households are often impacted by other variables such as poverty, absence of basic amenities and fewer life choices. It is in these circumstances that we see potential for collaboration between social work with visual and performing arts as a strengths based approach to community development to unleash the locked capital of culture and create more vibrant communities by empowering people's 
inherent strengths with the unlocking of their creativity (Riggs and Pulla, 2014). Arts practice has been in use in health, education community works sometimes as adjuncts and sometimes as a means to develop the practitioner or as a means of promoting the overall development of our client communities (Walton, 2012).

As authors of this paper we believe that arts practice cannot operate independently to regenerate the communities but in must be run conjunction with effective community development if it is to be useful in ameliorating the conditions of our social work clients.

While it is possible to talk about the richness and diversity of arts use in a number of human services fields, Walton's (2012) literature search for references to visual and sensory methods in social work suggested that social work is predominantly fixated on talk and text in seeking to develop and express its understanding of itself and its client stories. The focus of this paper has been to attempt to describe the efficacy of visual and performing arts approaches, hitherto not well known to social work education and community practice. The paper also draws shared concerns and commonalities between arts practitioners and social work practitioners in the field of community work.

A visual artist who works with paint, clay, mosaics, drawing and found objects, Anne Riggs; a professional actor and director that uses skills of mime, clowning and physical comedy, Alex Pinder; and a community development trained strengths based social work practitioner, Venkat Pulla decided to put their diaries, conversations, photographs and permitted narratives of their clients through a process of triangulation to write this paper. This combination of professional experiences and insights allowed us to see and interpret the effects of art in the community from a range of points of view. Through this process we bring a unity to our interpretative experience and demonstrate the collaborative opportunity of arts practice and social work as a potential to develop and promote coping skills, build resilience and thus enhance communities (Walton, 2012).To this end, we draw on reflections of arts practice participants, their observable behaviours and the art produced, coupled with the social work analysis of context. We utilised a narratological approach whereby the structure and nuances of the stories told by arts practice participants were phenomenologically analysed and the meaning of the arts practice identified and interpreted by the researchers to afford meaning making and interpretation.

\section{Common Concerns between Arts Practice and Social Work}

Artists and social work practitioners engaged in community work have several shared concerns. Children, families and communities with whom we work are impacted by a number of variables such as absence of basic amenities, poor education, discrimination and limited opportunities and choices. All of us come in contact with individuals, groups and communities expressing trauma, mental and other illnesses. There is also a prevalence of drug and alcohol addiction, poverty and isolation that depletes the individual's capacity to function well, let alone contribute to society.

Community development practitioners are always looking for innovation and creativity so that people not only survive and cope, but emerge from their situation with daring and resilience (Pulla, 2013). Research with individuals and groups who have experienced trauma shows that participating in community creative practices enhances a sense of meaning and purpose in their life, reduces the effects of trauma, improves social interactions with others, develops their enjoyment and helps them name and express a complete range of emotions. Or, as defined in their own terms, closer to potentially full and productive lives, (Riggs, 2010, 2012a, 2012b).

Creative practice as part of community development is gaining considerable recognition in some sectors (such as in the fields of refugee settlement, trauma recovery and disability) and a growing body of evidence supporting its efficacy is emerging. However, creativity and arts-based community development practice has yet to be widely embraced in the domain of international community development as an informed practice to enhance efforts to address social issues. Non-government organisations (NGOs) rarely include arts as integral to their programs and few of the large NGOs are even prepared to trial its efficacy.

Through writing this paper we present our argument for consideration of arts practice within the prevailing ethos of social work and community development and we invite social and community development workers into collaborative and participatory creative practices with artists in order to strengthen existing trends of arts and artist-led community development One of the better-known definitions of arts based community development comes from William Cleveland (2002) who defines it as "an arts centred activity that contributes to the sustained advancement of human dignity, health and or productivity with a community". His full definition suggests the inclusion of creative activities that educate and inform us about the world and ourselves, are known to inspire and mobilize individuals or groups, nurture and heal people and/or communities and build and improve community capacity and or infrastructure (Cleveland, 2002).

Arts practice has been included in health, education and community development; it works as an adjunct to other interventions, sometimes as a means to develop the practitioner, or sometimes as a means of promoting the overall development of our client communities (Walton, 2012). It would appear that arts practice cannot operate independently to regenerate communities, rather its efficacy lies when it is part of a creative collaboration, offered in 
conjunction with effective community development and when deployed as part of a wider program of development, such as those facilitated through local councils or in groups involved in a meliorating conditions of our social work clients. Different arts forms, including visual and performing arts, all have relevance and have been discussed as part of social work practice in recent years (Walton, 2012).

\section{Exploration of a Shared Vision}

As authors, we believe that arts and social/community work practitioners have a shared vision for creative inputs into client solutions. Herein, we explore some of the ways in which the arts have and can be effectively utilized, either in collaboration or as inspiration, for community development workers (in which we include social workers, teachers and community leaders).

\section{Tracing Commonalities}

Artists, social workers and community development workers work with the most vulnerable and abandoned in the community. Common to arts practitioners and social workers in community practice is that both are invited into private spaces and share in the deeply personal experiences of our clients; we work in a range of places and alongside a variety of people that would be unusual in most other professions. We witness and immerse ourselves in humanity at its most celebratory, vulnerable, wretched and ordinary. Common to these two practices is:

- Maintenance of a clear specific focus

- Goals with imaginative yet defined outcomes

- An emphasis on representing the objective reality

- Frequent review of progress

- Discarding ineffective interventions and reinventing where needed.

\section{Arts in Community Practice}

To a question: what is it to being an artist in community? Anne Riggs says:

In many respects, artists are like outsiders, although largely out of choice. The artist's practice may be viewed with bewilderment, but that may mean the viewer is being closed to what an artist does. We have a range of skills which, when applied to community development, provide unique and valuable contributions to wellbeing.

Artists are careful observers of people and 1hings. Artists employ constructive and healthy practices to express and communicate, especially about those feelings 1 hat are hidden and silenced, ugly and abject. Artists view the human body as a 1 hing of beauty, wonder and expression; we are able to assist those whose bodies have been abused and who feel alienated from them, to re-inhabit their body with comfort and understanding. Artists demonstrate that an individual can claim, maintain and honour difference without removing her/himself from the community, shedding individuality or being trampled on by others. We demonstrate how to be resourceful, lateral and imaginative in thinking and doing and believe 1hat these qualities are to be celebrated. As artists, we see that determination and effort are important ingredients in creativity and to appreciate 1hat passion, pleasure and beauty are worthy desires to pursue (Riggs, 2010).

\section{Anne Riggs also reflects that:}

An enduring sense of otherness was captured in 1he much-used phrase, "me and the outside world", used by arts program participants who had been sexually abused.

In its bluntness this phrase holds the inheritance of the being the 'other': the immense feelings of difference and alienation, the sense of aloneness and unworthiness and the lack of care shown to them; the "destruction of the soul", as sexual abuse victim Carole Stingel describes it (Robinson, 2007). Trauma, mental and other illness, drug and alcohol addiction, poverty and isolation further alienates them from society.

There are many ways in which a community can engage meaningful arts practice: one is through viewing, another is through participation. "It (art) has the ability to transgress stifling conventions and boundaries, resist oppressions, grieve and heal, produce inter subjective knowledge ... and come to terms with multiple and contradictory identities' (Bochner and Ellis, 2003).

Artist Antony Gormley considers the process of art-making as a journey of discovery and recovery; "[It is]"an instrument for thinking, or perhaps (since thinking cannot be divorced from being) a catalyst for new states of being and an artwork may initiate transformations in both maker and viewer" (Nesbitt, 1993, p. 13). McCarthy et al. argue that the language of "art fills the gaps left by communication based on the natural science model of knowledge that dominates our culture" (McCarthy, Ondaatje, Zakaras and Brooks, 2004, p. 43). For strengths based practitioners in community development this definition is crucial in that it links the individual's journey through arts practice to a new state of being, to that of being empowered which, in turn, can be utilized as a strength or a building block for development of the community (Pulla, 2012).

The extraordinary community work, Field for the British Isles ${ }^{1}$ conceived and facilitated by Gormley is an example of a community working together to bring forth artwork and responses that would have been impossible for any individual to create alone. Gormley explains that when people work together they "begin to sense themselves as a collective body, even when previously unknown to each

1 Hayward Gallery, London, viewed by the second author 1996. 
other and at the same time create an image of that collective body" (Nesbitt, 1993, p. 32). The creative act of making art together with all that happens around it, opens a space for healthy human exchanges, a space for caring relationships to develop naturally, to throw quips in and ideas around, get advice from others, ease tensions and normalise relationships significantly. The exposure to a larger slice of humanity opens participants, many of whom lead very isolated lives, to reconsider prejudices and engage differently with the world around them.

An example of arts practice that compliments strengths based social work practice to build, foster and enhance communities is illustrated from the second author's experiences from an on-going program at the South Eastern Centre against Sexual Assault (SECASA) ${ }^{2}$ in Melbourne conducted with women survivors of sexual abuse Upon reflection, the participants could see how their lives had been distorted by trauma and abuse. Significantly, throughout their narratives they have reported that these distortions frequently led them away from others into deep and unhappy isolation and to holding unusual views of how others were likely to think and behave. A sense of normality, as is commonly understood, is frequently absent from the lives of those who have experienced trauma, abuse and prejudice. Many participants expressed a desire to "feel normal" and "be normal". Words, such as usual, typical, common, healthy or natural-useful alternative words in some circumstances-mostly fail to convey the feelings victims of trauma and abuse are striving for-that is, to achieve a sense of connection and to disable the concept "me and the outside world", a term many use (Riggs 2010).

Reflecting on the concepts of normal (and abnormal), Waltraud Ernst (Ernst, 2006) notes how differently this is considered, interpreted and contested across a range of disciplines, such as science, philosophy and the social sciences. The word 'normal' has many connotations and can often be burdened with an implied moral overtone; its meaning is constantly being reviewed and reinterpreted as society itself evolves, which can make its use problematic. It is, however, a word commonly used in everyday language and is frequently used by participants to describe how they feel, how they did not feel or how they wanted to feel. In the context of this paper, the terms 'wellbeing' or 'mainstream' may be reasonable substitutes for 'normal', but neither can be used linguistically in the same way, nor does either accurately communicate how one might feel, think or behave in relation to others. For social work, the term 'normal' in this

2 South Eastern Centre Against Sexual Assault (SECASA) is one of Victoria's fifteen Centres against Sexual Assault (CASA) and work to ensure that women, children and men who are victim/survivors of sexual assault have access to comprehensive and timely support and intervention to address their needs. SECASA also works towards the elimination of sexual violence through community and professional education, informing government policy, advocating for law reform and facilitating research to increase community understanding of the nature and incidence of sexual assault. SECASA provides a crisis service and follow-up counselling and other services throughout the south-eastern region of Melbourne. www.secasa.com..au context may be extended to mean empowered, in that an individual who feels isolated, broken and abnormal, can categorically be a defining place from which to build a community.

Normality seems like an unlikely goal for an arts project. It reeks of conformity, suburbia and ordinariness. Normality, however, can be celebrated for the predictability of going about our lives, doing the shopping, visiting friends, learning something new; ordinary things we do and enjoy because we feel secure in our environment, safe in the company of others, confident in our choices and worthy of doing things that nurture our body, mind and spirit. It would be hard to imagine any community group gathered together for a significant amount of time without laughter, stories and food also being present. So it is with community arts practice. Although, traditional counselling methods may make some in roads into changing the views of a person at an individual level, they do not address community attitudes or the structure of the community that enabled the trauma in the first place and they certainly do not facilitate change at the community level. Arts practice as a means to strengths based community development performs all of these roles; it empowers individuals, raises awareness, highlights community strengths and weaknesses and facilitates positive change.

The transcript below, words of a participant in an arts program run by the second author is from a video blog ${ }^{3}$; it describes her journey of coping, resilience and recovery and shares a similar sentiment to the term 'functioning well'. The link between art, empowerment and community building is also highlighted.

My name is Vanessa-I am doing this because I found help through the agency and through the art groups and I would like to make a difference to other people like myself, if I can so by doing this, if this encourages just one person to seek help, then I am happy. I am one of 11 children-three different fathers for those eleven children; I have never met my father. Every one of my brothers and sisters has drug, alcohol and emotional problems, which is a shame. Everyone else in my family is criminal, drug addicts, alcoholics-so that is where I come from! I was very depressed all the time. I spent most of my time alone at home-- wallowing in my own misery until they convinced me to come along to the art group. I was not very eager to do that-I didn't like being around people and I found it very hard to sit in a large group of my peers. But it was amazing. From the very start I felt comfortable. It took a few weeks to get in to it-then it totally started me changing who I was and getting me out of the rut that I had gotten myself into over the years-which is easy enough when you have been abused.

3 Available for viewing http://secasagroups.blogspot.com. au 


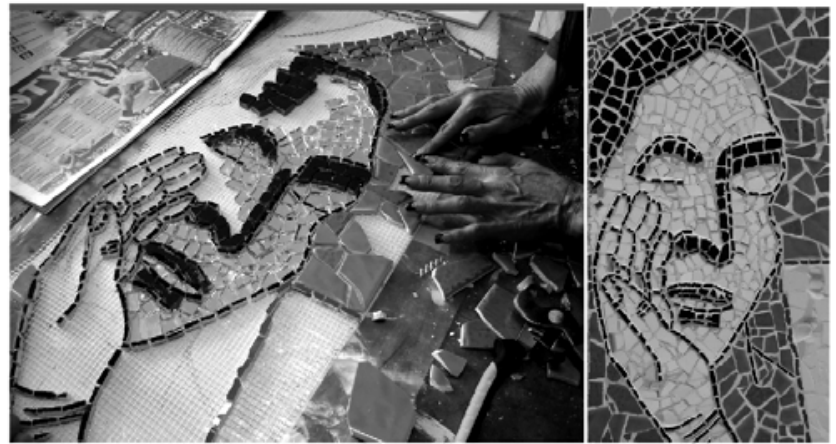

Figure 1. Mosaic onto Discarded Domestic Items, Made as Part of an Installation by Victims of Sexual and Family Abuse. Group Mosaic Project onto an Ironing Board with Vanessa

Being involved in the group (the mosaic group was the first one I was involved in) started me off being a bit more normal with people. I made some friends and I was also seeing my counsellor at SECASA. I was 'understanding' my trauma a bit more and coming to terms with it. At the same time being involved in the art group and making friends was changing my life at home. I finally had real friends, decent people who I could relate to and talk to if I needed to, who were all exactly like me and been where I have been, to different degrees. With the mosaics-I had never done it before-but I did want to give it a go. I had always been interested in it-I had even saved some things over the years to do it but never did. But once I started I didn't realise how much actual work was in it. I became very good at cutting-and began teaching the teacher how to it!!!! No, not really. No, but we even started up a little group---where several of us got together at my place for quite a few months. We thoroughly enjoyed getting together, chatting, doing art together, comparing all the things we had done, learning techniques from each other because everybody is good at one thing and somebody is good at another. It has just been a really wonderful, positive experience and the first time in my life where I have been involved in something that is just positive for the sake of doing something and having the fun of doing something as well. And creating beautiful artwork when you are feeling really horrible is a great way to get rid of that nastiness and anger out of your body.

The sense of 'functioning well' in social and family situations can mean a renewal, or even a rediscovery, of the community and its innate strengths. Adherents of the strengths perspective do not believe, with good reason, that most people who are the victims of abuse or that all people who have been traumatized inevitably become "damaged goods" (Saleebey, 2000, p. 129). Clearly, we are unaware of the upper limits of human capacity to grow and change, therefore, the message is to take the individual, group and community aspirations seriously. In community development, the process is to build communities hopes, values, aspirations and visions (Pulla, 2012).

In another narrative that symbolises the intrinsic value of an arts practice, one participant survivor of childhood sexual abuse described her life as devoid of anything that most people consider normal; this had been her reality for so long that she struggled to comprehend what a normal life might be. "My pain is so great, that fun just didn't have any meaning any more".

Itmade me feel a bit normal even-because I didn't feel abnormal and I generally do. I usually feel really alienated from normal people and I didn't feel that. You know I could almost be happy with the class.

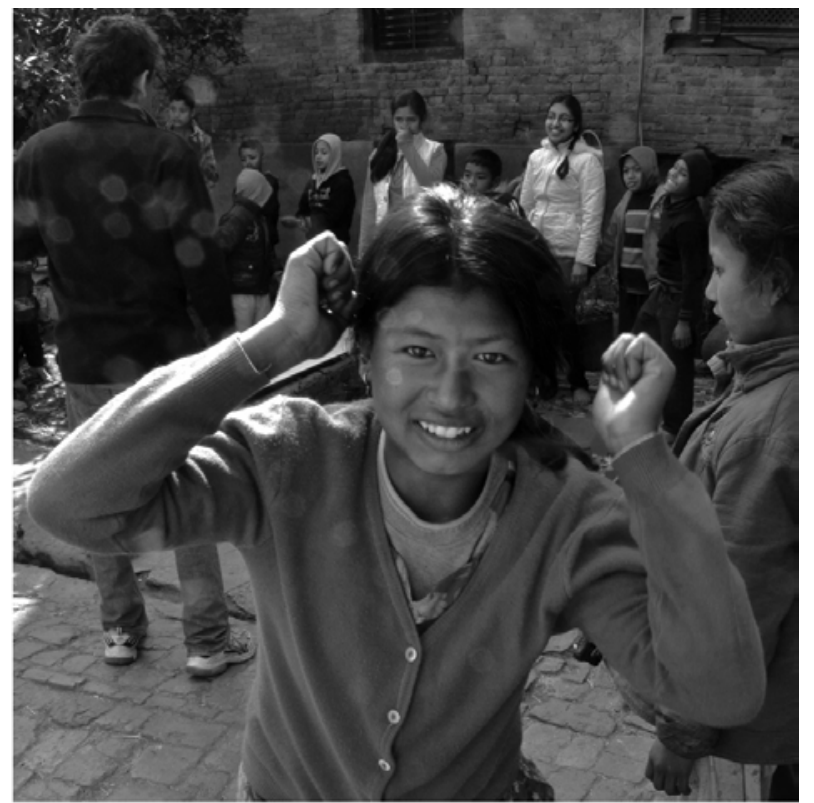

Figure 2. Nepali Street Child Participating in Drama Class with Alex Pinder and Anne Riggs. Artists in Community International, 2014

Pleasure and joy are some of the "intrinsic values of the arts experience" (McCarthy et al. 2004, p. 68), as enjoyment comes with the achievement of excellence in rather than from the direct pursuit of pleasure (Csikszentmihalyi, 1997). We add that it also comes when the work yields meaning for the maker (and others). This concept relates to social work from a strengths perspective, in that, when linked to achievement, pleasure is considered a step towards self-esteem and thus, empowerment. As fun, like pleasure, joy, beauty and friendships can be lost in the shadow of vulnerability, much is gained when these are reinstated or become a presence in the life of an abused person.

If dysfunction in our communities is multi-causal it is equally important to find multivariate interventions in response. The performing arts offer projective meaning opportunities to help us understand our clients and communities. Social workers would be interested in the conscious and unconscious feelings, conflicts and motions that individuals experience as the performing arts introduces an opportunity to explore. This form of art and particularly mime and clowning, is useful when dealing with groups and communities, as is not restricted by text and language, it is 
fun and is accessible to people of all ages and ability. Alex Pinder, a performing artist from Australia, in describing his work with the children in the saltpans of India, believes that having 'fun' can be the worthy function of participating in the performing arts.

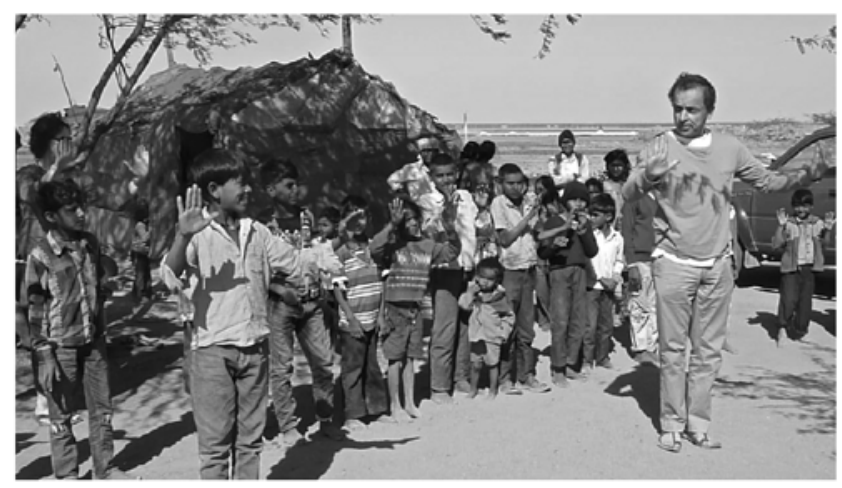

Figure 3. Performing Artist, Alex Pinder, Leading a Mime Workshop with Children in the Saltpans and Anne Riggs, India. Artists in Community International Project, 2014

Alex Pinder in conversation with the first author of this paper:

The use of performing art forms, such as mime, storytelling, or comedy varies depending upon what we wish to see as end results. Do we wish that the group or community enjoy and have fun? Do we envisage that the marginalised community's current reality is exposed to sensitize to the larger community? Do we wish to use the art form as tool for learning-to build concentration, teamwork and skills in learning to learn? The built-in purpose makes a big difference.

The clowning techniques used here with the children are also useful for adults. They are born of great traditions in the art form. The spontaneity and transience of the movements build a great relationship between my learners and me (Pinder, 2013).

\section{Performing Arts in the Community}

Alex Pinder graduated from L'Ecole Jacques Lecoq Paris, France and brings with him skills of mime, movement, clowning and physical comedy, improvisation and role play to his own work and his work with Anne Riggs. In this transcript below, from an Artists in Community International video "The First in Two Million Years $/{ }^{\prime 4}$ Alex describes the environment of the project, his concerns about where to pitch the project and the response of the participants. Dhanraj Malik is the local community leader who instigated the project.

Alex: This is a view of the saltpans in the Little Rann

4available on YouTube: www.youtube. com/watch'lv=-f7MQ!BfdWI of Kutch, in Gujarat, the western state of India. We first went there to look at the wildlife-the birds, the wild ass. But there is something else that we discovered about this place...

There are families who live in the desert-they have been hired as labourers-and their job is to make salt from the water harvested from the monsoon, as the rainwater filters through the desert. They live in appalling conditions and work long hours in extreme heat. Families have little access to health care and child mortality is very high. They have very little access to fresh water or fresh food and they can live there for up to nine months of the year. They basically have nothing.

Community Leader Dhanraj Malik: The whole idea of going to the saltpan children is that it was a new exposure for them because they have never done painting or acting ever in their life.

Alex: Because the children had no access to television or film, I wondered whether they would understand the comedy. We created scenes in mime showing them cooking and their eating, as well as doing some of the classical mime exercises. They really got it. They really understood it and enjoyed it. We did some basic clowning as well, which they laughed at. That was the whole idea of the day-that they had a good time.

Adults were on the periphery and were totally engrossed by it. There were mothers who joined in with the painting and a lot of the fathers helped hang up the flags we created. We were surprised with how well the children focussed and we wondered whether it was because they had so few distractions like so many other children. They really understood and enjoyed the clowning, which made me think just how universal it is.

Dhanraj Malik: It is something they will never forget for the rest of their lives. We had a great day and they had big smiles on their faces and I am very grateful for the two of you for doing that.

In an earlier visit to India with an International NGO, the second author and Alex Pinder were asked to develop a project to bring awareness to the prevailing issue of child labour, a main concern of that NGO. This awareness campaign was a national undertaking. Alex Pinder says:

Rather than take a didactic approach to this complex practice and risk alienating our host country and participants, we chose to focus both visual and performing arts projects on the rights of children to learn, to play and to have fun and from that, other forms of expression arise.

Some may describe play as a childish form of activity however play involves basic drives and makes an important contribution to psychological and physical wellbeing. Art 
and art-making also includes the creation of works that are "disturbing dizzying, despairing, disorienting and are not in any natural sense, pleasurable" (McCarthy et al. (2004, p. 47). "In approaching our work with the children through fun and pleasure, we were able to help children reach places where they were able to create comic sketches drawing attention to what was lost from their lives, to their unmet needs and to the violence which they regularly confronted as part of their everyday life as child labourers" says Pinder.

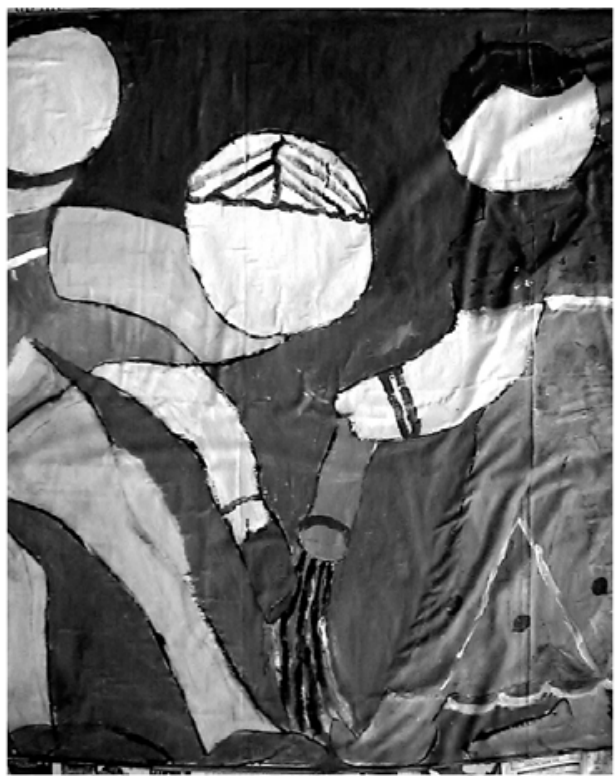

Figure 4. Students in India Explore Child Labour Themes Through Arts Practice

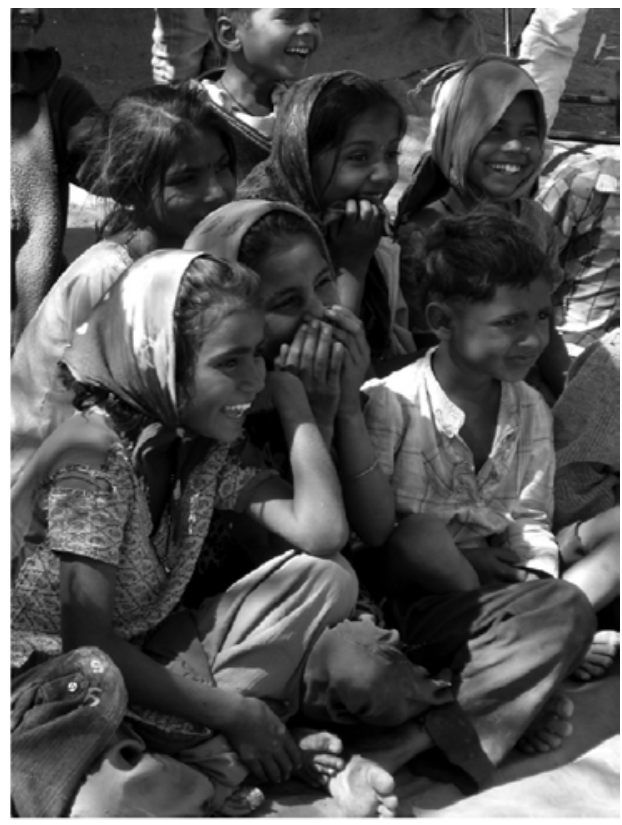

Figure 5. Children Who are Usually at Work in the Saltpans Enjoy Watching Their Friends Perform Clowning Skits During the Art and Drama Program. Their Turn is Next! Artists inCommunity International, 2014.

One tradition of clowning, giving the vulnerable 'little guy' the opportunity to have the 'upper hand' and finally win at the expense of the oppressor, created much laughter and gave the children the kind of pleasure which is reached in when art relates powerfully to our own experiences and emotions (McCarthy et al. 2004, p. 47). The fulfilling pleasure of giving expression to what is seen, lived, heard and felt is different from the kind of pleasure felt when encountering most forms of entertainment and therefore its value is anchored in to our cognitive, emotional, imaginative interactions with them.

"Apart from the creativity side, it's about something that I am actually doing for me, because I really like it and it gives me that sense of pleasure, joy and happiness for myself, not for anybody else and so it has helped through just little things. When sad moments come into my life or bad stuff comes into my life, just by cutting a tile, it has really helped" (SECASA participant). This is a perfect demonstration of arts practices in community development work complimenting a strengths based theoretical model for social work practice; assisting in the building of coping skills and developing their strengths. The simple act of cutting of a tile eases pain, empowers to cope and builds resilience. Individual resilience can then be utilised by the adept social work practitioner to develop and extend communities.

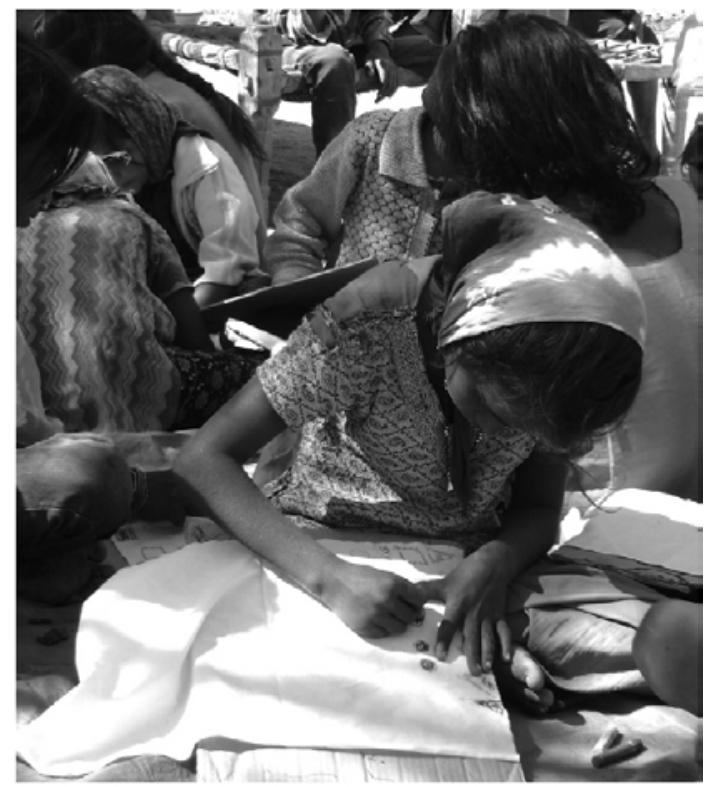

Figure 6. Children of the saltpans in India are absorbed in their arts practice. These children have little access to education or exposure to the arts; they nonetheless were captivated by this project. Artists in Community International, 2014.

One distinctive characteristic of arts practice is that captivation often leads to imaginative flight; Weinstein (in McCarthy et al., p. 46) describes art as an exhilarating emancipation, "a magic venture out of our own precincts and into something rich and strange". We tend to grasp and express things through art in ways that is rare in everyday life which enables participants a departure from one's everyday self, the state of helpless distress and inability to effect meaningful change. As the individual's capacity to 
perceive, feel and interpret the world of everyday experience is enhanced through this intense engagement, so the space for new possibilities is opened up.

Creative collaborations with arts practitioners further the efficacy of a strengths approach to tap the wisdom, knowledge and experience of clients and communities. Nonetheless, we are locked into the "one size fits all" practices that do not always serve individuals and communities well by reducing the opportunities for human our observation that, sitting adjunct to their professional business, that those we spouse as the helping professionals often don't recognise the healing capacities of art intervention. The following diary notes provide illustration:

The second author visits her relative in a high-care nursing home and on these visits she also engages with other residents with dementia. The scene is typical of the lounge room: a television is on always on, although the residents hardly watch nor understand it, there are no other activities available to them on a Sunday and few residents get visitors.

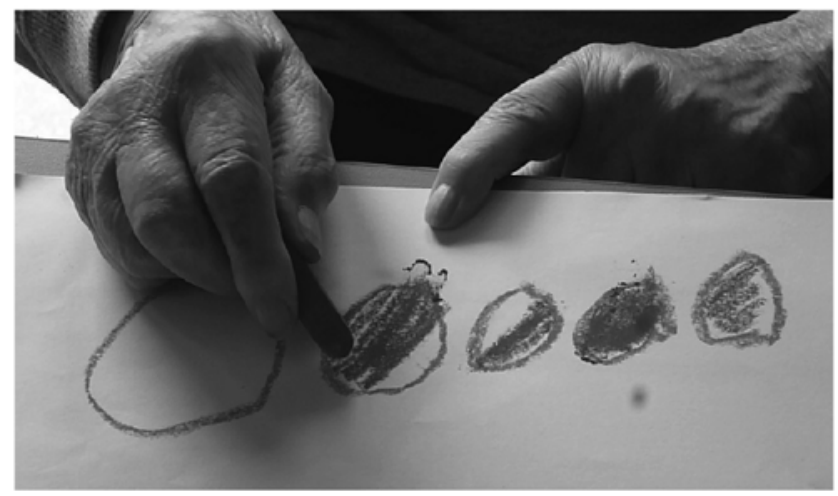

Figure 7. Elderly Women Concentrating on Drawing, Melbourne Nursing Home, 2013

I offer the residents some colour pastels and paper and ask if they would like to draw. A couple of them respond to the invitation. They need encouragement and motivation from me to get started and to stay interested. Soon the evening duty nurse comes in expresses excitement at seeing one resident's drawing: 'Did she do that?' The resident is usually in a near-constant state of agitation, but doing the drawing she is calm and focussed. Nonetheless, he wants to wheel one after the other to bed. I try telling him, 'let her be for a while, she is drawing' but the duty nurse does not give her any more time to complete it as it is bed time, at 4 pm'

\section{Strengths Approach to Communities}

Empowerment theories identify and help individuals and communities to recognise barriers and dynamics that allow oppression to persist and to recognise circumstances and actions that promote change, empowerment and liberation (Robbins, Chatterjee, and Canda, 2006, Pulla, 2012). Considering that the strengths perspective is a proactive process used to build on people's uniqueness, aspirations, strengths, resources and resiliency as well as to engage in actions highlighting embedded power dynamics, pursuing social justice and personal well being it can be considered a theory of empowerment Itis composed of two interdependent, interactive and simultaneous dynamics; personal and social empowerment with its axiom being the client provides direction to the process self-determination and the accessing of resources and opportunities to both play an important role in his or her environment and in its shaping. In Cleveland's (2002) definition of arts-centered activity, cited above, suggests the inclusion of:

- Activities that educate and inform us about ourselves and the world

- Activities that inspire and mobilize individuals or groups.

- Activities that nurture and heal people and/or communities

- Activities that build and improve community capacity and/or infrastructure (Cleveland).

The parallels indicate once again a territory for a combined approach of arts in social work.

Joshua Guetzkow asks 'the question of how to link micro-level effects on individuals to the more macro level of the community" in seeking to understand the impact of the arts on communities (Guetzkow, 2002 p. 15). This has given pause for thought by the authors leading to the questions: Can we indeed separate the individual from community in the first place? Can we argue that a person who is isolated, banished, or simply disengaged and not participating in community life is therefore not part of the community? Can we argue that exclusion or reduction indicates that some form of development and integration is needed? 'How can we link micro-level effects on individuals not participating to the more macro level of the community"?

Consistent themes from SECASA participants has been their profound loneliness, anchored in shame, silence and a sense of 'otherness' referred to above, experienced by victims of abuse before attending the art group. Consistent are the revelations about mental illness, drug and alcohol addictions, chronic pain and illness, inability to work, deep feelings of pain and loss and suicidal thoughts: feelings and responses linked to the abusive past and the aching lack of social support. We cannot change the past, but as evidenced above, arts programs develop strong and meaningful ways for participants to create or find, then participate in community life.

If creativity is inherent to being then to not foster that creativity, to not allow for its inherent ability to heal the psyche and create hope from hopelessness is then an impingement on all that social work aspires to do. For strengths based practitioners, creativity is the first strength upon which we can build the foundations for a new community as it inspires hope and achievement and enhanced self-esteem. To utilise this form of therapeutic practice seems an imperative. 


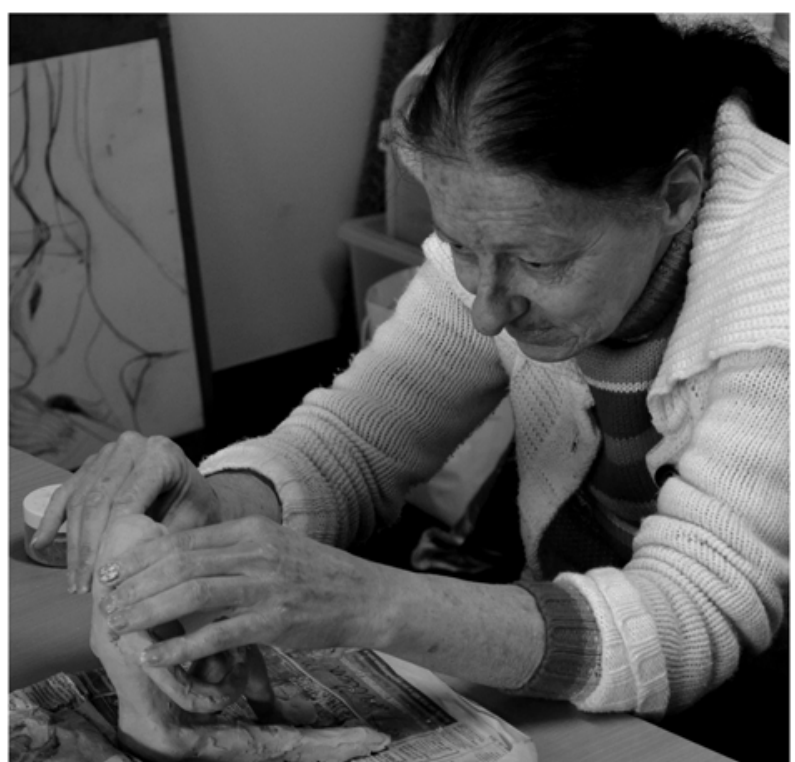

Figure 8. Woman survivor of sexual abuse and family violence expresses her loss and grief through art, but also finds a community who understands her past and with whom she can share a future.

MK Smith quoting Buber describes the communication between humans, whether through language or silence as 'the sphere of the between" (Smith, 2001). "We can only grow and develop, according to Buber, once we have learned to live in relation to others, to recognize the possibilities of the space between us. "All real living is meeting," he says". For those individuals who are not 'meeting', it could be argued that many are 'not living'. Only today one new participant described feeling the "No.1 lonely person in the world" as a result the trauma and its ongoing isolating effects: "Life is just there, I am not living it". 5

\section{Discussion}

In this paper we have attempted to bring attention to the benefits arts practice can offer to social work clients and to the development of the communities. Well-considered community arts projects, facilitated by artists, enhance the use of language of repair and healing, a response to care (Stokes, 2010). That arts practice builds and fosters self-esteem and empowerment, adds richness to lives once forgotten and allows individuals to rebuild has been demonstrated in this paper. As part of an experience of shared learning between client, artist and strengths based practitioners, arts practice can assist in the creation of new directions for individuals and communities. People who find new hope and vision through arts practice rejoin their communities in new ways and have potential to foster change within that

5 SECASA participant conversation with A. Riggs. community. The strengths based practitioners can readily utilise this tool as an adjunct to their work, to promote resilient and purposeful communities that respect and honour the journeys of their members.

Stokes argued that artists are at the service of their others and social work and community workers feel the same way. We each see our professions as being compassionate and open to emotions. Dori Laub, a psychoanalyst specialising in trauma, insists that, like psychoanalysts, "artists on trauma" have "an internal other", a part that is compelled to look beyond the surface, to grapple with and express the underlying testimony of the individual experience (Laub, 2002). The artist witnesses the crushing sense of pain, the losses, the fragilities and frailties within the community and as Stokes describes, the "tending" and "attending" of identity and culture - a form of care, through a practice of participatory making facilitates the transformation of complex human needs and aspirations into concrete form or performance, rousing sense of resurgence and hope for the future. If that were so, why would we not add the sensitivity and usage of arts practice in social work with communities?

Social work concerns include working with conscious and unconscious feelings, conflicts and motions that individuals and communities experience. It greatly concerns itself with dealing with dysfunction in communities. The practitioner is aware that such concerns are multi- causal therefore requiring multivariate responses. We consider that the creative arts offer a range of opportunities to explore and better understand the mindset of our communities.

Uppermost amongst the aims of community development is to enhance the lives of individuals and communities, to leave them with a range of new skills, which includes creative ways, to enhance personal coping, resilience and building hope (Pulla, 2013). We have argued that participation fostered through creative interactions with artists enhances individual and community relationships and understanding and therefore community development. The growing recognition of the arts in community programme policies in developing, as well as developed, nations is an indication that strong and meaningful arts programs that are not constrained by text and language are seen to be having some profound impacts on individuals and communities.

Our research suggests that social work and arts practice in the field of community development has been largely sporadic, a chance meeting. A deliberate plan is needed for a sustained approach to exploring the potential of creative collaborations and bringing the social work and creative professions together to discuss its usefulness through forums such as conferences, seminars and presenting our work through journal articles and books are some ways of achieving this. Including arts practice in the BA Community Mental Health and AOD (Chisholm TAFE, Melbourne) is one example of inroads being made into furthering the broad social work and community development fields of mental 
health, particularly at the crucial point of tertiary education. Further action- research is needed.

We are always surprised, delighted, touched and amazed by what we uncover, enable and witness. Participants-sometimes for the first time---experience joy, hope and a more complete sense of wholeness. When so much is possible with so little... we imagine and dream... what would be possible with some deliberate and sustained support to arts practice in community development.

Note: all images in this paper are by Anne Riggs.

\section{REFERENCES}

Bochner, Arthur P. and Ellis, Carolyn (2003). An Introduction for the Arts and Narrative Research: Art as Inquiry. Qualitative Inquiry, 9(4), 506-514.

Cleveland, William (2002). Mapping the Field: Arts-Based Community Development Retrieved 4 July 2009, from http://www.communityarts.net/readingroom

Ernst, Waltraud (2006). The Normal and the Abnormal: Reflections on Norms and Normativity." Histories of the Normal and the Abnormal. In W. Ernst (Ed.), Histories of the Normal and the Abnormal. (pp. 1-26). London and New York: Routledge.

Guetzkow, Joshua (2002). How the Arts Impact Communities: An introduction to the literature on arts impact studies. Paper presented at the Taking the Measure of Culture Princeton University.

Laub, Doti (2002). The Art of Survival, A Conversation with Doti Laub MD, Featuring Ben Miller and Petra Schweitzer, PhD, March 28, 2002. Reading On, a journal of theory and criticism. Vol. 1 Issue 1, Fall 2006. Retrieved 06.06.2009, from http://readingon.library.emory.edu

Maizels, John (1996). Raw Creation. Outsider Art and Beyond. London: Phaidon.

McCarthy, Kevin F., Onaatje, Elizabeth H., Zakaras, Laura and Brooks, Aurhur (2004). Gifts of the Muse: Reframing the Debate about the Benefits of the Arts. Santa Monica: Rand.

Mollica, Richard and SothearaChhim with Natasha Mitchell. (2005). Healing Genocidal Trauma: North Meets South [Radio], All in the Mind. Australia: ABC Radio National.

Nesbitt, Judith (Ed.). (1993). Antony Gormley. Liverpool: Tate Gallery.
Pulla, Venkat. Coping and Resilience and hope building International Conference, Brisbane, page $N$ - and $\mathrm{V}$ Presidential Speech (Editor: 50 pages) ISBN 97809802994-2-7 Brisbane

Pulla, Venkat. (2012). 'What are strengths-based practices all about? In Pulla, V., Chenoweth, L., Francis, A., Bakaj, S. (Eds). Papers in Strengths-based Practice, New Delhi: Allied Publishers.

Pulla, Venkat (2013). Contours of Coping and Resilience: the front story, in V. Pulla, A. Shane, A., Warren, S. (Eds.), Perspectives on Coping and Resilience, Authors Press, New Delhi.

Riggs, Anne (2010). The Creative Space, Art and Wellbeing in the Shadow of Trauma, Loss and Grief. Unpublished PhD thesis. Victoria University,

Melbourne (2012a). Art in the Shadows. In Venkat Pulla, A. Shatte and S. Warren (Eds.), Perspectives in Coping and Resilience. Delhi: Authorspress.

(2012b). The Un'not'ting. Paper delivered to international Strengths Based Practices Conference

(2013). A Message in a Bottle: Vanessa's Story. Video commissioned by South East Centre Against Sexual Assault www.artistsincommunity.me.

Riggs, A. Out of shadows, into the light: Resilience and Coping Skills through Arts Practice in Pulla, V., Shatte, A. and Warren, S. eds., (2013 Perspectives on Coping and Resilience, New Delhi: Authors press Global Network www.authorspressbooks.com

Robinson, Natasha (2 February 2007). Clark victim calls for police action, The Australian.

Saleebey (2000). Power in the People: Strengths and Hope 129 Advances in Social Work 129--130.

http://www.state.il.us/DCFS/docs/LCPhaaeV/Dennis_

Saleebey_Article.pdf Advances in Social Work, Vol. 1, No. 2.

Schmid, Therese (Ed). (2005). Promoting Health Through Creativity. For professionals in health, arts and education. London and Philadelphia: Whurr Publishers.

Smith, M.K. (2001). Community. Encyclopedia of Informal Education. http://www.infed.org/coromunity/cornmunity.htm.

Stokes, Maryanne (Pip) (2010). A Poetics of Care: mourning, consolation, healing., unpublished thesis, Melbourne University, Melbourne.

Walton, P. and Patricia Walton (2012). Beyond Talk and Text: An Expressive Visual Arts Method for Social Work Education, Social Work Education: The International Journal, 31:6, 724-741. 